\title{
A METOdologia RESOLUÇÃO DE PROBLEMAS POR MEIO DE JOGOS NO ENSINO DE CIÊNCIAS NA PERSPECTIVA DE GALPERIN
}

\section{THE METHODOLOGY PROBLEM SOLUTION BY GAMES IN THE TEACHING OF SCIENCES IN THE GALPERIN PERSPECTIVE}

\author{
Silvana Lopes Goiabeira ${ }^{1}$ \\ Cristina Maria Costa do Nascimento ${ }^{2}$ \\ Patrícia Macedo Castro ${ }^{3}$
}

\begin{abstract}
RESUMO: Este artigo aborda reflexões com bases epistemológicas sobre o uso da metodologia resolução de problemas no Ensino de Ciências em consonância com o lúdico na perspectiva teorizada por Galperin. Considerando a dificuldade por parte dos educadores em utilizar a problematização no contexto do Ensino de Ciências e as deficiências dos estudantes em solucionar problemas, o objetivo do trabalho é apresentar princípios capazes de nortear o professor em sua prática docente a fim de despertar no aluno a um olhar reflexivo sobre conhecimento científico por meio de situação problemas com a utilização de jogos educativos articulado com a Formação por Etapas das Ações Mentais. Fundamentado em pressupostos para o seguinte questionamento: Como aplicar a metodologia resolução de problemas por meio de jogos educativos como estratégia de aprendizagem no Ensino de Ciências seguindo a teoria de Formação por Etapas Mentais de Galperin com alunos do ensino fundamental? Por fim, nas considerações conclusivas, destacam a importância da prática pedagógica abalizada na resolução de problemas para aquisição no Ensino de Ciências, tendo como ferramenta os jogos educativos na perspectiva da Teoria de Galperin.
\end{abstract}

Palavras chave: Ensino de Ciências, Lúdico, Resolução de Problemas e Formação por Etapas das Ações Mentais.

ABSTRACT: This article approaches reflections with epistemological bases on the use of the methodology of problem solving in the Teaching of Sciences in line with the ludic in the perspective theorized by Galperin. Considering the difficulty of educators in using problematization in the context of Science Teaching and the students' deficiencies in solving problems, the objective of the work is to present principles capable of guiding

\footnotetext{
${ }^{1}$ Mestrada do Programa de Pós Graduação em Ensino de Ciências, pela Universidade Estadual de Roraima - UERR. Boa Vista, Roraima, Brasil. E-mail: slg2.sg@ gmail.com

${ }^{2}$ Mestrada do Programa de Pós Graduação em Ensino de Ciências, pela Universidade Estadual de Roraima - UERR. Boa Vista, Roraima, Brasil. E-mail: cris_lavor@hotmail.com

${ }^{3}$ Doutora em Ciências Biológicas (Zoologia). Professora do Programa de Pós Graduação em Ensino de Ciências, pela Universidade Estadual de Roraima - UERR. Boa Vista, Roraima, Brasil. E-mail: patriciacastro@uerr.edu.br
} 
the teacher in his teaching practice in order to awaken in the student a reflective look on scientific knowledge through situation problems with the use of educational games articulated with the Training by Mental Action Steps. Based on assumptions for the following question: How to apply the methodology problem solving through educational games as a learning strategy in Science Teaching following the theory of Galperin Mental Stage Training with elementary school students? Finally, in the concluding remarks, they emphasize the importance of pedagogical practice based on solving problems for acquisition in Science Teaching, using as educational tools the perspective of Galperin Theory.

KEYWORD: Science Teaching, Play, Problem Solving and Training by Stages of Mental Actions.

\section{INTRODUÇÃO}

No cotidiano nos deparamos com diversos problemas que exige de nós formas diferentes de pensar e as mais variadas ações para resolvê-las. Estamos imersos numa sociedade cada vez mais competitiva em relação à produtividade humana e exigente quanto às decisões mais eficientes e eficazes para resolução de problemas.

Neste sentido, o artigo apresenta reflexão de se trabalhar à resolução de problemas no Ensino de Ciências por meio de jogos educativos com estudantes, no intuito de instigar os mesmos a se sentirem mais motivados na própria busca do desconhecido, o lúdico sendo sobreposto na solução de problemas. Tendo como objetivo apresentar princípios capazes de nortear o professor em sua prática docente a fim de despertar no aluno a um olhar reflexivo sobre conhecimento científico por meio da situação problemas com a utilização de jogos educativos articulado com a Formação por Etapas das Ações Mentais. Fundamentado em pressupostos para o seguinte questionamento: Como aplicar a metodologia resolução de problemas por meio de jogos educativos como estratégia de aprendizagem no Ensino de Ciências seguindo a teoria de Formação por Etapas Mentais de Galperin com alunos do ensino fundamental?

O artigo expõe teorias nos aspectos epistemológicos para compreensão da construção cognitiva do indivíduo, ressaltando alguns fatores que contribuem no processo de aprendizagem no Ensino de Ciências.

\section{RELEVÂNCIA DO ENSINO DE CIÊNCIAS NO CONTEXTO ESCOLAR}


É indiscutível que a educação é fundamental para o desenvolvimento do indivíduo e, consequentemente, da sociedade. O Ensino de Ciências como parte da estrutura curricular educacional vem contribuindo na formação de cidadãos e cidadãs críticos a serem mais participantes no pleno exercício de cidadania.

Para que essa participação seja efetiva, a base curricular deve contemplar reflexões a respeito das interferências do homem no meio ambiente e suas relações interpessoais a fim de levantar discussões para a promoção de uma consciência social e planetária (Brasil, 1998).

Diante deste contexto muitos questionamentos são levantados sobre como esse ensino tem sido levado para o educando, e qual o fruto dessa aprendizagem no âmbito social, já que o Ensino de Ciências contempla temas tão relevantes, como: saúde, meio ambiente, tecnologias, entre outros. Será que esse ensino tem apresentado uma ciência dinâmica, flexível, criativa, questionadora, ética ou tem caracterizado "a ciência como um produto acabado e inquestionável: um trabalho didático-pedagógico que favorece a indesejável ciência morta." (Delizoicov; Angotti; Pernambuco, 2011, p.33).

É necessária a superação do senso comum pedagógico, das práticas tradicionais esgotadas. Ghedin (2012, p.17) comenta que "[...] o conhecimento escolar deve nutrir-se basicamente de conhecimento científico", ou seja, a escola deve elevar a qualidade de seu ensino. Essa ação de "nutrir-se" do saber científico promove a elevação do educando, que começa a romper com o conhecimento comum movido pelo espírito científico que "deseja saber, mas para, imediatamente, melhor questionar" (Bachelard, 1996, p.21).

O Ensino de Ciências não pode ser fundamentado sem questionamentos, apenas com instruções teóricas desarticuladas e vazias sem significação real para o aluno. $\mathrm{O}$ discente precisa compreender a importância do conhecimento científico na sua essência.

Alguns dos objetivos dos Parâmetros Curriculares Nacionais ( $\mathrm{PCN}^{\prime}$ s) é que o aluno seja capaz de exercer sua cidadania de forma legal, ser agente transformador do ambiente, ter responsabilidade individual e social, despertar questionamentos e ser criativo, dinâmico, reflexivo na busca de soluções (Brasil, 1998).

O Ensino de Ciências ao contemplar esses objetivos pode contribuir na construção do sujeito como agente transformador tanto do meio quanto do seu próprio conhecimento. 
[...] o professor ou a professora de Ciências Naturais precisam abrir o diálogo, encontrar respostas e incentivo adequados para o amadurecimento crítico de seus alunos, o que significa, geralmente, empreender trabalho em grupo, capaz de envolver e de colocar os alunos em interação social e cognitiva. A complexidade desta fase escolar exige que o professor tenha possibilidade real de realizar ensino ativo, desafiador e atualizado (Brasil, 1998, p.57).

É interessante que o aluno perceba que o Ensino de Ciências tem limitações de respostas frente a todas as suas inquietações e problemáticas isso se deve a sua fragmentação e parcialidade (Ghedin, 2012). Para superar essas deficiências entra a interdisciplinaridade, que vai operacionalizar a interação entre as diversas disciplinas fazendo a interlocução sobre determinado tema.

Para Ghedin (2012, p.40), “[...] é importante que se diga: uma perspectiva interdisciplinar só é possível quando as disciplinas escolares têm possibilidades reais de diálogo entre elas [...]", ou seja, o professor em ocasiões oportunas vai mediar à interação entre os conhecimentos.

Fonseca (2011) esclarece que o objetivo da educação é “[...] ensinar a aprender a aprender como complemento do ensino de matérias ou disciplinas, dotando os estudantes com pré-requisitos cognitivos que lhes permitam aprender com mais eficácia no futuro.” (p.72).

A importância disso, é que no Ensino de Ciências, diante de um tema abordado, poderá surgir um confronto de uma situação problema e o aluno vai poder trilhar em um campo maior do conhecimento, construindo hipóteses e buscando possibilidades para testá-las. Isso torna o ensino dinâmico, ou seja, abre-se um leque de alternativas em pesquisas científicas. Diante disso, faz necessários planejamentos que promovam melhoria de problemas do cotidiano.

\footnotetext{
Ao planejar cada tema, seleciona problemas, que correspondem a situações interessantes a interpretar. Uma notícia de jornal, um filme, uma situação de sua realidade cultural ou social, por exemplo, podem-se converter em problemas com interesse didático (Brasil, 1998, p.28).
}

Sem dúvida, o ensino deve ser pensado com ações pedagógicas que provoquem no aluno reflexões, instiguem-no a um olhar problematizador da realidade que o circunda, na busca do novo, sendo o professor como mediador desse processo e o aluno como sujeito ativo da aprendizagem. 


\section{RESOLUÇÃO DE PROBLEMAS NO ENSINO DE CIÊNCIAS}

Quando falamos na metodologia resolução de problemas não é algo tão simples de discorrer. A própria trajetória da Ciência na história da humanidade tem rompido barreiras em virtude dos avanços tecnológicos, descobertas científicas, produção humana, desenvolvimento social, sustentável, entre outros, na conquista de novos desafios.

No momento em que o conhecimento científico é instrumentalizado atua significativamente na promoção da evolução da Ciência frente ao próprio ato de formular problemas, isso desencadeia no homem uma atividade cognitiva instigadora, pois segundo Bachelard (1996, p.18) “[...] os problemas não se formulam de modo espontâneo.”.

Apesar da prática de um ensino acabado ser recorrente em muitas práticas pedagógicas, a própria necessidade de conhecer mais, para saber mais, não é algo novo.

\footnotetext{
$\mathrm{Na}$ antiguidade, assumia-se o fato da importância da atividade intelectual do indivíduo na compreensão dos processos e fenômenos da realidade. Sócrates utilizava o método de perguntas para promover a discussão, a dúvida e a solução de problemas. $\mathrm{Na}$ atualidade os pesquisadores na área da pedagogia procuram alternativas metodológicas, para favorecer uma aprendizagem ativa, que desenvolva o pensamento dos alunos. Assim, J. A. Carmenius, J. J. Rousseau, I. G. Pestalizzi, J. Dewey, em seus trabalhos pedagógicos explicitaram suas preocupações com a necessidade da aprendizagem favorecer o trabalho independente e criativo dos alunos (Silva; Núñez; Ramalho, 2001, p.1).
}

A construção do conhecimento se dá por meio de discursos, problematização, inquietação do homem sobre sua realidade, é um processo gradativo de descobertas e rupturas com o aparente, essas ações fazem parte da construção histórica da humanidade.

Para Bachelard (1996), o verdadeiro espírito científico é aquele que se opõe, questiona e pergunta, assim, afirma que "[...] todo conhecimento é resposta a uma pergunta. Se não há pergunta, não pode haver conhecimento científico. Nada é evidente. Nada é gratuito. Tudo é construído.” (p.18).

A troca de conhecimentos distintos muitas vezes produzem contradições desafiadoras que concorrem para a compreensão dos problemas gerados em determinadas situações em sala de aula. 
Muitas vezes o que para um professor pode parecer um problema relevante, significativo, aos olhos dos alunos o mesmo problema pode ser algo trivial que carece de sentido (Echeverría; Pozo, 1998).

Um problema cognitivo do aluno, no que tange na necessidade de assimilar e resolver o contraditório pode ser definido no seguinte aspecto:

\begin{abstract}
O problema representa a própria contradição, que caracteriza uma situação problema já assimilada pelo estudante, como resultado da identificação com o conflito cognitivo, que pode se revelar, quando se assimila a contradição de forma consciente e com possibilidades de explicitá-la, e que possa constituir um recurso metodológico organizado nas atividades investigativas do aluno (Silva; Núñez; Ramalho, 2001, p.4).
\end{abstract}

Na perspectiva escolar segundo os PCN’s a condução da problematização provoca movimentos essenciais no desenvolvimento cognitivo do discente, a formação de conceitos adquire significados na vivência do aluno e o mesmo passa a analisar as situações problemas com um maior grau de generalização e abstração, ou seja, o conhecimento científico torna-se significativo para o indivíduo (Brasil, 1998).

Nesse sentido podemos observar que a atuação da escola é muito mais complexa tanto no âmbito epistemológico quanto no contexto histórico-cultural, pois sua ação deve colocar o conhecimento num estado de mobilização, gerando transformação movida por um processo de inquietação a favorecer o progresso científico. Ghedin (2012, p.25) afirma que, “A escola tem uma missão insubstituível: garantir que certo número de saberes e de saber-fazer seja adquirido por todos de maneira sistemática e organizada".

De acordo com Fonseca (2011) o papel da escola está relacionado a uma educação cognitiva, que promove a criatividade psíquica do educando e sua capacidade de resolver problemas. Sobre ainda esta reflexão, Fonseca $(2011$, p.7) discorre que:

Aprender a refletir, a raciocinar, a utilizar estratégias de resolução de problemas para adaptarmos as novas gerações para aprender mais, melhor e de forma diferente flexível, é uma necessidade fundamental da educação e, provavelmente, a tarefa mais relevante da escola. Todo estudante tem o direito de desenvolver ao máximo o seu potencial cognitivo [...]. 
No ambiente escolar a problematização deve ser pensada como meio de confrontar as vivências e conhecimentos prévios dos alunos com conhecimentos científicos e reestruturar suas ideias fundamentada em conceitos próprios da Ciência (Brasil, 1998). A atuação do professor é fundamental nesse processo, trazendo informações pertinentes, levantando questionamentos, apontando relações e conduzindo a classe a questões desafiadoras.

Nesse contexto referente ao ensino problematizador proposto por Majmutov (1983) alguns princípios para aplicação das situações problemas são apontados, na seguinte forma:

[...] a) das explicações do professor em condições de situações problemas, b) da análise independente (com ajuda do professor) de situações problema, c) da formulação de problemas e sua solução mediante o planejamento do problema (lógico e intuitivo) de suposições e hipóteses e d) de sua fundamentação e demonstração, mediante a verificação do grau de correção da solução (Majmutov,1983 apud Tintorer; Mendoza, 2012, p.05).

É importante destacar que o interesse do aluno depende da contextualização feita pelo professor das questões levantadas sobre determinados temas, de maneira a mobilizá-los a aprendizagem em decorrência de possíveis significados pessoais e sociais contidos nas situações problemas (Brasil, 1998). Vejamos um exemplo:

[...] supondo-se uma classe trabalhando com o tema da alimentação nos seres vivos. Frequentemente os estudantes já sabem que os animais se alimentam de plantas, de outros animais ou de ambos. Todos já cultivaram plantas ou cuidaram delas. Por isso, sabem que estão fixadas no solo, que recebem água, adubos e que se desenvolvem na presença de luz. Possivelmente, pensam que as plantas se alimentam da terra e da água que consomem pela raiz. Sabe-se, entretanto, que as plantas produzem seu próprio alimento energético no processo da fotossíntese, no qual a água, a luz do sol e gás carbônico do ar são usados para a obtenção de glicose (Brasil, 1998, p.120).

Nesse momento o professor estimula um clima de indagação cognitiva no aluno, cria questões estratégicas que levarão os alunos a necessitar de determinados conteúdos.

Que perguntas poderão gerar conflitos sobre a alimentação das plantas? Como poderão compreender que a terra não é alimento para as plantas? Por exemplo, o professor poderá perguntar à classe: "Se as plantas retiram alimento da terra, por que a terra dos vasos não diminui?", "Como explicar o fato de algumas plantas sobreviverem em vasos apenas com água?" e "Como algumas plantas vivem sobre outras plantas, com as raízes expostas (algumas samambaias, orquídeas)?” (Brasil, 1998, p.120). 
O professor não deve apontar "isso é um problema" o aluno que deverá identificar isso como um desafio, o próprio contexto vai trazer uma inquietação cognitiva.

Se o professor quer ensinar algo e despertar o interesse do aluno tem que apresentar o desconhecido, o misterioso, o conhecimento desejado, pois aquilo que está em evidencia não provoca questionamentos, aliás, produz acomodação. Ele não pode entregar conceitos já elaborados, prontos ao aluno, pois, a aprendizagem é construída pelo próprio aluno a partir de suas investigações e possíveis descobertas.

$\mathrm{Na}$ presença do sentimento de inquietação o aluno busca respostas que podem ser coerentes, plausíveis, capaz de solucionar o problema ou não, essa ação ou reação move o aluno a aprender a fazer e consequentemente a aprender a aprender. Nesse ínterim surge a necessidade do conteúdo, onde o aluno começa a enxergar algumas contradições do que sabia e do novo saber ocorrendo uma reestruturação cognitiva, é nesse momento então que os conceitos científicos começam a fazer algum sentido para ele.

\footnotetext{
No processo da problematização os estudantes farão tentativas de explicação segundo suas vivências, e isso pode ser insuficiente para a situação em estudo. Conflitos de compreensão e de explicação podem acontecer no processo. A participação do professor passa a ser fundamental para que as vivências e conhecimentos atinjam novo patamar, mais próximos das explicações próprias da Ciência. Cabe a ele trazer os conceitos científicos para o contexto, a fim de que contribuam no entendimento da situação e na resolução dos problemas constituídos no processo (Brasil, 1998, p.119).
}

O aluno irá analisar alguns pontos da situação problema, como: quais os elementos do contexto (o conhecido e o desconhecido)? De que forma poderá ressignificar aquela informação? O que estará faltando de conhecimento? E quais os caminhos para a solução através de levantamentos de hipóteses e suas possíveis comprovações? Então, ele precisa compreender o problema, estabelecer um plano, executar o plano e examinar as soluções obtidas.

Esse desafio frente ao desconhecido é que chama a atenção, que impulsiona o aluno a querer saber, promove um prazer pela descoberta e no decorrer do processo vai se especializar na resolução de problemas.

\section{PROBLEMATIZANDO POR MEIO DO LÚDICO}


Como instrumentalizar esse saber problematizador no contexto escolar de maneira a dinamizar a atuação do aluno nesse processo? A seguinte indagação fomenta a discorrer sobre o uso de jogos educativos na abordagem de um ensino movido por situações problemas no Ensino de Ciências.

Antes de adentramos na definição de jogo como recurso educativo é interessante diferenciar o tipo de ação lúdica utilizada na mediação entre os envolvidos. A ação lúdica escolhida pode ser caracterizada por elementos essenciais: a situação lúdica ou a atitude lúdica.

\begin{abstract}
A situação lúdica (...) não é uma atividade imposta, a participação é livre e voluntária. Os participantes criam para si um mundo diferente do mundo habitual e estabelecem certos limites de tempo e espaço, que devem ser respeitados. É uma situação de natureza incerta quanto ao produto; não é possível determiná-lo com antecedência, pois tal atitude tiraria o caráter imprevisível do jogo, que excita e fascina os jogadores (...). A atitude lúdica é outro fator que colabora na compreensão de certa atividade como jogo, pois os participantes demonstram de forma bastante visível, nas suas atitudes, indícios de divertimento, fascinação, distração, excitação, tensão, alegria e profundo envolvimento emocional na atividade (Lima, 2008, p.144).
\end{abstract}

A atitude lúdica é o próprio jogo em si, dentro de um formato e regras estabelecidas, motivacional e eficiente quando articulada a objetivos educacionais específicos. Na perspectiva de Huizinga (2000) o conceito de jogo é muito amplo, varia de acordo com a situação vivenciada, o meio, a cultura, as relações, ou seja, o próprio percurso histórico do homem, entre algumas definições apresenta a seguinte:

O jogo é uma atividade ou ocupação voluntária, exercida dentro de certos limites de tempo e espaço, segundo regras livremente consentidas, mas absolutamente obrigatórias, dotado de um fim em si mesmo, acompanhado de um sentimento de tensão e alegria e de uma consciência de ser diferente da vida cotidiana (Huizinga, 2000, p.24).

A palavra jogo em muitos casos retoma a ideia de brincadeira e as lembranças recobram o período da infância, isso não é um mero acaso, pois este sentimento está intrínseco ao desenvolvimento humano.

Segundo Oliveira (2005), Vygotsky discute o papel do brinquedo no desenvolvimento infantil, e traz um destaque a brincadeira "faz de conta" (brincar de casinha, escolinha, etc.), que mesmo sendo uma ação imaginária está regido por regras, onde estas possibilitam um avanço de suas ações a um patamar mais elevado pelo fato de a criança começar a imitar funções de adultos ou de objetos inanimados. Segundo 
Oliveira "O brinquedo provê, assim, uma situação de transição entre a ação da criança com objetos concretos e suas ações com significados.” (2005, p.66), ou seja, a criança se relaciona com o significado das coisas e não com o próprio objeto.

Nesse sentido o brinquedo envolve aprendizagem e promove o desenvolvimento, pois a criança transita no imaginário regido por regras que estão entrelaçadas a uma determinada cultura, portanto seu comportamento vai sendo moldado a essa cultura, em contrapartida a construção da sua psique vai se formando a partir dessas experiências.

Para compreensão do desenvolvimento do indivíduo Vygotsky define três zonas de desenvolvimento: real (ZDR) - é o nível que a criança já chegou; potencial (ZDP) é o nível que a criança ainda não chegou, mas que podemos imaginar que está próximo de acontecer, pelo fato de determinada ação necessitar ainda da ajuda de um mediador; proximal (ZDp) - nível que a criança está passando pelo processo de maturação. “[...] o brinquedo cria uma ZDp na criança. No brinquedo a criança comporta-se de forma mais avançada do que nas atividades da vida real também aprende a separar objeto de significado." (Oliveira, 2005, p.67).

\begin{abstract}
A zona de desenvolvimento proximal define aquelas funções que ainda não amadureceram, mas que estão em processo de maturação, funções que amadurecerão, mas que estão presentemente em estado embrionário [...] permite-nos delinear o futuro imediato da criança e seu estado dinâmico de desenvolvimento, propiciando o acesso não somente ao que já foi atingido através do desenvolvimento, como também àquilo que está em processo de maturação. [...] O estado de desenvolvimento mental de uma criança só pode ser determinado se forem revelados os seus dois níveis: o nível de desenvolvimento real e a zona de desenvolvimento proximal (Vygotsky, 1991, p.58).
\end{abstract}

Rego comenta que, “A criança poderá utilizar materiais que servirão para representar uma realidade ausente, por exemplo, uma vareta de madeira como uma espada [...]" (1995, p.81). Esses materiais podem ser incorporados em uma situação lúdica de jogo.

O jogo, fonte privilegiada de desenvolvimento proximal, promove avanços nas capacidades humanas superiores: de pensamento, imaginação, memória, linguagem, atenção, concentração, motricidade, socialização e domínio da vontade. Por meio dos jogos e das brincadeiras, a criança amplia de maneira significativa e criativa o conhecimento de si, dos objetos, da natureza e do contexto social no qual está inserida (Lima, 2008, p.145). 
Se pensarmos nesse ângulo um suposto aluno do $8^{\circ}$ ano que participe de uma brincadeira "faz de conta do corpo humano", tem sua identidade mudada passando a representar determinado órgão (digamos que seu papel é imaginar ser um coração - pelo lúdico vai informar sua estrutura, sua função, etc.). Outro exemplo bem oportuno é o jogo de trilha do corpo humano, o aluno pode ter acesso a imitações dos órgãos do corpo humano e, reportar o significado do órgão existente nos humanos a essa imitação. Isso pode ajudá-lo a compreender por meio de representações materiais ou simbólicas os conceitos científicos de forma mais perceptível e significativa. Essa atividade externa colabora para o seu desenvolvimento intelectual.

No primeiro momento possa ser que o aluno ainda não tenha compreensão das estruturas do corpo, mas o professor é responsável em auxiliá-lo, conduzindo-o da ZDR (daquilo que ele sabe) para a ZDP (daquilo que ele poderá saber), através da mediação da ZDp que é justamente a maturação de certos conceitos na sua estrutura cognitiva.

“[...] a zona de desenvolvimento proximal pode revelar aos professores o que realmente o aluno precisa aprender, pois o fato da mediação ajudá-lo a resolver problemas que não conseguiria realizar espontaneamente, o torna apto para internalizá-los no futuro.” (Vieira; Ghedin, 2012, p.149).

O jogo como recurso de resolução de problemas no Ensino de Ciências juntamente com a mediação do professor em auxiliar o aluno no processo de transição do conhecimento, durante a maturação de ideias e formação de conceitos que evoluem pela zona de desenvolvimento proximal, se utilizado com objetivos claros e um planejamento estratégico torna-se aliado do professor como ferramenta de ensino e para o aluno como recurso motivador da aprendizagem.

Neste sentido o jogo é apenas um dos possíveis itens de instrumentalização onde as informações são conduzidas em uma linguagem simbólica transitando de um plano externo para um nível intelectual, cujas operações se processam a um nível mental superior colaborando para a construção cognitiva.

Os PCN's mencionam os possíveis recursos e meios que podem favorecer o Ensino de Ciências, dentre eles cita os jogos:

Ao contrário, diferentes métodos ativos, com a utilização de observações, experimentação, jogos, diferentes fontes textuais para obter e comparar informações, por exemplo, despertam o interesse dos estudantes pelos 
conteúdos e conferem sentidos à natureza e à ciência que não são possíveis ao se estudar Ciências Naturais apenas em um livro (Brasil, 1988, p.27).

De acordo com as Orientações dos PCN’s para o Ensino Médio (Brasil, 2006), o jogo é um instrumento que pode trazer benefícios tanto ao professor quanto ao aluno, pois estimula a aprendizagem e torna o ambiente mais propício para o desenvolvimento criativo, espontâneo, aumentando a capacidade de comunicação e expressão dos alunos, e estes passam a ter um novo olhar dos conhecimentos envolvidos por intermédio do lúdico. Quanto ao professor, possibilita novas técnicas ativas de ensino que favorecerão seu trabalho docente.

Monteiro e Ghedin (2012) mencionam a necessidade da utilização de jogos no Ensino de Ciências em concordância com o trabalho de Leontiev sobre a teoria da atividade que destaca a importância da ação lúdica no ato de promover operações intelectuais nas crianças.

\footnotetext{
Com relação aos conteúdos de ciências naturais, o professor necessita viabilizar as suas aulas através de materiais concretos, que possam proporcionar nas crianças ou adolescentes condições de inquietação a exemplos a recomendação do uso de jogos que Leontiev (2001) ressalta, cabe ao professor adaptá-los aos conteúdos que será desenvolvido, tendo em mente que as ações que os estudantes deverão realizar devem ser orientadas para se atingir o objetivo (Monteiro; Ghedin, 2012, p.168).
}

Podemos compreender que quando o estudante está envolvido em um jogo que o estimula a resolver problemas, esse recurso se torna apenas um falseador lúdico onde o foco são as situações problemas que desencadeiam a atividade cognitiva, pois esta é movida por um esforço intelectual por parte do aluno e o jogo didático pode ser considerado mais um instrumento externo, interposto entre o aluno e o objeto de estudo, que é o próprio conhecimento em processo de construção.

Neste sentido, pode-se inferir que este recurso mediado pela metodologia resolução de problemas pode contribuir durante o processamento da formação das etapas das ações mentais de Galperin.

\section{PRESSUPOSTOS TEÓRICOS QUE COLABORARAM PARA PROPOSTA DE GALPERIN}


Um marco na psicologia soviética e de grande influência na educação no que diz respeito a compreensão da natureza cognitiva humana foram os estudos feitos por Lev Vygotsky, que trouxeram uma abordagem sociointeracionista trazendo em destaque as funções mentais superiores, que são os mecanismos psicológicos mais complexos que diferenciam os homens dos outros animais (Oliveira, 2005).

De acordo com Oliveira (2005), essas funções refletem no desenvolvimento do indivíduo numa relação mediada com o mundo real através de instrumentos e signos que auxiliam na atividade humana.

Nessa perspectiva Oliveira (2005) ressalta que Vygotsky afirma em seus estudos que é pela ação do homem sobre a natureza através do trabalho que vínculos são construídos com o auxílio de instrumentos no meio externo e signos no campo psicológico, seus estudos evidenciam também a linguagem como outro fator preponderante de transformação, isso significa que a cada desafio enfrentado pelo homem no contexto social novos fenômenos emergem e surge assim a cultura e a história.

Em um novo prisma A. N. Leontiev colaborador de Vygotsky desenvolveu a Teoria da Atividade, que também destaca a relação do sujeito com o mundo través da atividade, sendo que a origem desta atividade é advinda de uma necessidade que é impulsionada por um motivo em direção a um objeto (Talízina, 1988 apud Tintorer; Mendoza, 2012). Algumas críticas Leontiev direciona ao trabalho de Vygotsky quando comenta que:

“[...] não são os conceitos (nem, por conseguinte, os significados nem os signos nem instrumentos), senão a atividade real que une ao organismo com a realidade circundante, o que determina o desenvolvimento tanto da consciência em seu conjunto com algumas funções psíquicas." (Talízina, 1988 apud Tintorer; Mendoza, 2012, p.03).

$\mathrm{Na}$ concepção de Leontiev o homem apodera-se da cultura produzida historicamente, internaliza-a e só então, humaniza-se, essa dinâmica promove transformação não só dos objetos, mas dele próprio potencializando o desenvolvimento de suas capacidades humanas (Núñez; Oliveira, 2013).

\section{ETAPAS DAS AÇÕES MENTAIS DE GALPERIN}


Galperin, pesquisador soviético, trouxe contribuições na organização do processo ensino-aprendizagem, na valorização do trabalho do professor e na formação de conceitos que resultaram na formulação da Teoria da Formação das Etapas Mentais, cujas bases científicas tiveram como referencial os estudos de Vygotsky em relação ao conhecimento da linguagem interna e externa. $\mathrm{O}$ aprofundamento desses estudos sobre a internalização da linguagem externa permitiu Galperin estabelecer relações entre atividade externa, matéria e atividade interna, esse entendimento despontou na formulação de sua teoria sobre as etapas mentais (Tintorer; Mendoza, 2016).

Galperin foi colaborador de Leontiev, e membro da escola fundada por Vygotsky. Seu foco de estudo era a relação dos processos mentais com o mundo externo físico. Seus estudos trouxeram esclarecimentos em relação a Teoria Histórico Cultural de Vygotsky (Tintorer; Mendoza, 2016).

Algumas críticas, Galperin direciona sobre a Teoria da Atividade de Leontiev quando ressalta que não é qualquer atividade o objeto da psicologia, mas apenas a atividade de orientação. Em relação aos trabalhos de Vygotsky queria compreender os conceitos complexos de mediação e interiorização na organização do ensino para o desenvolvimento dos estudantes. Suas pesquisas tinham a meta de estruturar o ensino para favorecer a aprendizagem e potencializar o desenvolvimento do pensamento das crianças (Núñez; Oliveira, 2013).

A Teoria da Formação das Ações Mentais de Galperin (1976) esclarece o processo de assimilação de conceitos junto a ações articuladas com apoio de objetos externos, que ao serem instrumentalizados promovem a construção mental que se processam em etapas passageiras que vão se organizando de modo ativo ao ponto de a integrar-se a psique.

Galperin (1976) estabeleceu etapas no processo de assimilação de conceitos partindo das ações externas para as internas considerando momentos de orientação, execução e controle da atividade. As etapas são as seguintes:

- Motivacional - gera o início das etapas, deve ser contínua em todas as demais ações.

- Base Orientadora da Ação (BOA) - sistemas de condições que permite a orientação, execução e controle da atividade.

- Etapa Material ou Materializada - mediação por objetos concretos ou suas representações. 
- Linguagem Externa - (verbal ou escrita), ausência de objetos ou representações materializadas, a linguagem assume função simbólica;

- Linguagem Externo para $\mathbf{S i}$ - ação interna dirigida a si mesmo ou a outrem.

- Linguagem Interna - a ação se reduz e se automatiza.

Vejamos essas etapas em uma possível situação pedagógica articulada a resolução de problemas em interação com jogos educativos. Primeiramente a ação pedagógica deve ser norteada pelo ensino problematizador a partir de contradições que motive e gere interesses nos alunos a necessidade de soluções articuladas com lúdico de forma a propiciar uma reação positiva para o estudo.

Segundo Nuñez e Pacheco (1998, p.99) comentam que Talízina, pesquisadora soviética, considera a etapa motivacional "[...] como etapa zero, em que ainda não há nenhum tipo de ação, nem são introduzidos conhecimentos; ela tem como tarefa principal preparar os alunos para assimilarem os novos conhecimentos".

Como apoio para o desenvolvimento da atividade a BOA torna-se essencial, assinalado por Galperin:

\footnotetext{
"A parte orientadora é a instância diretiva e, precisamente, no fundamental, depende dela a qualidade da execução. Se elaborarmos um conjunto de situações em que se deva aplicar essa ação conforme o plano de ensino, essas situações ditarão um conjunto de exigências para a ação que se forma e, juntamente com elas, um grupo de propriedades que respondem a essas exigências e estão sujeitas a formação" (Galperin, 1959 apud Nuñes; Pacheco, 1998, p.101).
}

A BOA auxiliará o aluno na compreensão da construção da atividade problematizadora mediada pelo professor, à elaboração do conhecimento transitará pela orientação, execução e controle das ações, nesses termos os conceitos deixam de ser estáticos e passam a ser móveis e ativos frente ao processo de resolução de problemas.

O problema pode ser representado externamente em forma lúdica de um jogo didático que é um instrumento manipulado pelos alunos (exemplo um jogo de cartas contendo informações do conteúdo, um tabuleiro, uma trilha sobre caminho do alimento no corpo, o uso de dados, etc.). Tais recursos ajudam na sistematização e organização do conhecimento, os quais possuem signos externos que representam determinados elementos da ciência (exemplo: a imagem de um órgão ou uma trilha desenhada em formato do sistema digestório) estes representados em um instrumento de manipulação que é o próprio jogo didático. 
Esses elementos funcionam como apoio concreto na ação do aluno sobre o contexto de uma situação problema. Podemos considerar essa etapa chamada de materializada, pois traz a exposição das representações do objeto de estudo, onde o aluno começa a realizar a ação e aplicação de conceitos interagindo com os objetos do jogo tendo como apoio a BOA.

Para o aluno compreender o problema implicado no jogo também precisa de uma representação interna, ter a compreensão de conceitos, para isso ocorrer é preciso percorrer algumas etapas mentais. Durante o processo de internalização pela manipulação dessas ferramentas (instrumentos e signos), o aluno vai se especializando, fazendo novas conexões sinápticas em um processo de evolução cognitiva, promovendo o nível da fala que já passa usar conceitos mais elaborados e expressar uma linguagem mais científica. É nesse contexto que a etapa verbal aflora e a ação se torna teórica.

Quando o aluno começa a verbalizar esses conceitos mesmo de uma forma tímida ele está estruturando suas funções mentais superiores, e começa a articular seus pensamentos durante a resolução dos problemas tornando a assimilação mais efetiva.

Cada vez mais "a fala torna-se intelectual, com função simbólica, generalizante, e o pensamento torna-se verbal, mediado por significados dados pela linguagem." (Oliveira, 2005, p. 47). Seu pensamento vai se tornando mais especializado com o uso da linguagem favorecendo a formação de conceitos antes não compreendidos.

Fazer relações mentais agora sem auxílio de mediadores, seja jogos ou a interlocução do professor, eleva o aluno à etapa linguagem externo para si, onde a linguagem se dá entre o próprio indivíduo, internamente, com auxílio não mais de objetos externos, mas de uma rede de signos que estruturam de forma mais complexa seu pensamento, tornando o aluno mais independente de interferências externas e apto a enfrentar novas situações.

Isso se dá pelo fato de o ser humano ter a capacidade de fazer relações mentais na ausência das próprias coisas, de usar sua criatividade e imaginação, fatores esses que não surgiram de uma hora para outra, mas que tem toda uma história de construção cognitiva no trajeto de sua existência.

O aluno vai se especializando, com a presença marcante de conceitos estruturados no cognitivo, a ação começa a reduzir-se e automatizar-se, agora a etapa da linguagem interna que é reflexo das ações material e verbal adquire caráter 
psíquico. A partir deste momento os conceitos já estão assimilados e estruturados no pensamento e não necessitam mais passar por todas as etapas anteriores, isso somente se processará quando novos conhecimentos ou conceitos forem apresentados e houver ausência de imagem mental correspondente à nova atividade ou situação problema.

Então os instrumentos (físicos), os signos (representações) e a linguagem são mediadores da atividade humana, ou seja, do trabalho que é a ação do homem sobre o mundo e sobre ele próprio, no caso aqui essa atividade é apresentada pelo "ato de estudar" que tem como objetivo de conduzir o aluno a novos conhecimentos, habilidades, atitudes e hábitos através da resolução de um determinado problema que o motivará a necessidade de buscar soluções sobre uma situação particular.

\section{CONSIDERAÇÕES FINAIS}

Uma prática pedagógica fundamentada em um ensino por resolução de problemas pode potencializar a assimilação dos conteúdos apresentados aos alunos no ensino de ciência através da problematização, desde que desperte o interesse do aluno e o traga a responsabilidade e ao desafio da solução.

Essa possibilidade torna-se mais efetiva quando articulada a recursos motivadores e desafiadores como propõe os jogos educativos, como ferramenta lúdica que possibilita o aluno a transitar por situações problemas, que podem ser discutidas coletivamente, favorecendo a reflexão a reestruturação de ideias, a formulação de hipóteses e pôr fim a internalização de conceitos científicos antes não compreendidos.

Para ajudar o aluno nesse processo de aprendizagem o professor necessita compreender os caminhos da construção cognitiva. Certamente, a teoria proposta por Galperin (1976), apresenta embasamentos cognitivos de como se processa a assimilação em determinados níveis das etapas mentais, dando assim, suporte ao professor na sua atuação como mediador do conhecimento.

Infere-se que quando um ensino problematizador trabalhado estrategicamente com jogos educativos e aplicado cuidadosamente a cada etapa mental, controlando, avaliando e corrigindo-as traz expectativas favoráveis quanto à qualidade do ensino e aprendizagem dos alunos.

\section{REFERÊNCIAS}


BACHELARD, G. A Formação do Espírito Científico: Contribuição para uma psicanálise do conhecimento. Rio de Janeiro: Contraponto Editora, 1996.

BRASIL. Ministério da Educação. Secretaria de Educação Básica. Orientações

Curriculares para o Ensino Médio: Ciências da natureza, matemática e suas tecnologias. Brasília: MEC/SEB, 2006. 135p

- Parâmetros Curriculares Nacionais: Ciências Naturais / Secretaria de Educação Fundamental. Brasília: MEC / SEF, 1998. 138 p.

DELIZOICOV, D.; ANGOTTI, J. A.; PERNAMBUCO, M. M. Ensino de Ciências: Fundamentos e Métodos. 4. ed. São Paulo: Cortez, 2011.

ECHEVERRÍA, M. D. P. P.; \& POZO, J. I. Aprender a Resolver Problemas e Resolver Problemas para Aprender. A solução de problemas. Porto Alegre: Artes Médicas,1998.

FONSECA, V. da. Cognição, Neuropsicologia e Aprendizagem: Abordagem neuropsicológica e psicológica. 5. ed., Petrópolis (RJ): Vozes, 2011.

GALPERIN, P. Y. Introdución a la Psicología: Un Enfoque Dialético. Madrid: Pablo del Río, 1976.

GHEDIN, E. Teorias Psicopedagógicas do Ensino Aprendizagem. Boa Vista: UERR Editora, 2012.

HUIZINGA, J. Homo Ludens. $4^{\text {a }}$ edição - reimpressão. São Paulo, SP. Editora Perspectiva S.A. 2000

LIMA, J. M. O Jogo Como Recurso Pedagógico no Contexto Educacional. São Paulo: Cultura Acadêmica: Universidade Estadual Paulista, Pró-Reitoria de Graduação, 2008. $157 p$.

MAJMUTOV, M. I. La Enseñanza Problémica. Havana: Pueblo y educación, 1983.

LONGAREZI, A. M.; PUENTES, R. V. (Org.). Ensino Desenvolvimental: Vida e Obra dos Principais Representantes Russos. Uberlândia: EDUFU, 2013.

MONTEIRO, D. M; GHEDIN, E. A Epistemologia de Leontiev, a Relação do Desenvolvimento do Psiquismo Humano, a Cultura e Suas Implicações para o Ensino de Ciências. In: Ghedin, E. (Org.) Teorias Psicopedagógicas do Ensino Aprendizagem. Boa Vista: UERR Editora, 2012. p 154-171.

NUÑEZ, I. B.; PACHECO, O. G. Formação de Conceitos Segundo a Teoria de Assimilação de Galperin. Cadernos de Pesquisa, n. 105, p. 92-109, 2013. 
NÚÑEZ, I. B.; OLIVEIRA, M. V. Ya. Galperin:. A Vida e a Obra do Criador da Teoria da Formação por Etapas das Ações Mentais e dos Conceitos. O Ensino desenvolvimental: vida, pensamento e obra dos principais representantes russos. Uberlândia: EDUFU, p. 283-313, 2013.

OLIVEIRA, M. K. Vygotsky: Aprendizado e Desenvolvimento, Um Processo SócioHistórico. São Paulo: Scipione, 2005.

REGO, T. C. Vygotsky. Uma Perspectiva Histórico-Cultural da Educação. Petrópolis (RJ): Vozes, 1995.

SILVA, S. F.; NUNEZ, I. B.; RAMALHO, B. L. O Pensamento do Professor: o Trabalho com Problemas no Ensino de Ciências. In: III Encontro Nacional de Pesquisa em Educação em Ciências - ENPC, 2001, Atibaia/ASP. Anais do III Encontro Nacional de Pesquisa em Educação em Ciências - ENPEC, 2001.

TINTORER, O. ; MENDOZA, H. J. G. Uma Aproximação das Teorias de Aprendizagem Significativa e Formação por Etapas das Ações Mentais. Aprendizagem Significativa em Revista. 2, p. 1-13, 2012.

Evolução da Teoria Histórico-Cultural de Vigotski à Teoria de Formação por Etapas das Ações Mentais de Galperin. In: Ghedin, Evandro; Peternella, Alessandra. (Org.). Teorias Psicológicas e suas implicações à educação em ciências. $1^{a}$. ed. , Boa Vista: Editora UFRR, 2016, p. 157-170.

VIEIRA, R.M.; GHEDIN, E. A Epistemologia Proposta por Vigotsky e suas Implicações para o Ensino de Ciências. In: Ghedin, E. (Org) Teorias Psicopedagógicas do Ensino Aprendizagem. Boa Vista: UFRR Editora, 2012. p. 139153.

VYGOTSKY, L. S. A Formação Social da Mente. São Paulo: Martins Fontes, 1991. 